\title{
Comparing visual perception on conventional cabinet tachistoscopes and computer monitor tachistoscopes
}

\author{
NANCY HUTNER \\ Holyoke Community College, Holyoke, Massachusetts \\ JEFFREY M. DUBOFF \\ GTE Internetworking, Burlington, Massachusetts
}

MARLENE OSCAR-BERMAN

Boston University School of Medicine, Boston, Massachusetts

and Department of Veterans Affairs Medical Center, Boston, Massachusetts

and

STEPHEN MUELLER

Baystate Medical Center, Springfield, Massachusetts

\begin{abstract}
Computer monitor-based tachistoscopes (using a cathode ray tube, CRT) and conventional tachistoscopes differ in experimental control over stimulus continuity, duration, and timing accuracy. This study evaluated the perception of visual stimuli presented with the two different types of devices. An experiment was conducted to compare recognition of visuospatial stimuli (random shapes) presented laterally and centrally in the visual fields for short exposure durations $(14,29$, and $43 \mathrm{msec})$, first with one device and then with another. Results indicated that the subjects' error rates and laterality patterns were similar on both types of tachistoscopes. It was concluded that perception of visual stimuli presented as continuous images on a conventional tachistoscope may be equivalent to perception of visual stimuli presented as pulsating images on a CRT. Further studies are needed using other types of visual materials to determine the range of visual stimuli for which both types of tachistoscopes measure equivalent perceptual processes.
\end{abstract}

Tachistoscopic presentation of visual stimuli is an important technique used by psychologists to study cognitive and neuropsychological functions. Computer-based tachistoscopes using the computer's monitor for stimulus presentation have virtually replaced conventional cabinet and projection tachistoscopes as the means of presenting stimuli. However, due to the nature of the raster-scan cathode ray tube (CRT) display employed in most computer monitors, stimuli presented on those monitors have certain fundamental differences from those presented on conventional tachistoscopes. These differences may have particular implications for (1) studies employing brief exposure durations, (2) studies attempting to determine visual thresholds or critical interstimulus intervals, and (3) perceptual laterality studies. The purpose of the present study was twofold. First, we sought to review the different properties of the two types of tachistoscopic presentation

This research was supported by NIAAA Grants R01-AA07 1 12, R37AA07112, K05-AA00219, and F32-AA05316 to Boston University and by funds from the Medical Research Service of the U.S. Department of Veterans Affairs. Correspondence should be addressed to N. Hutner, Psychology Department, Holyoke Community College, 303 Homestead Ave., Holyoke, MA 01040 (e-mail: nhutner@hcc.mass.edu). methods and to evaluate their limitations. Second, we determined experimentally the extent to which these differences would affect subjects' perception of stimuli that were presented centrally and in the lateral visual fields for brief exposure durations.

\section{TACHISTOSCOPIC PRESENTATION METHODS AND THEIR LIMITATIONS}

\section{Artifacts of CRT Images}

The image on a CRT consists of glowing regions of phosphor energized by electrons. In the raster-scan CRT used in most computer monitors, an electron beam (or group of three beams for most color monitors) scans the entire phosphor-coated screen in a series of parallel lines that form the raster. The electron beam is turned on, energizing the phosphor, when passing a point where the screen is to glow, and turned off where it is to stay dark. This raster-scan process takes about $35 \mu \mathrm{sec}$ per line in a common video graphics array (VGA) monitor, completely refreshing the screen in about 13-17 msec, depending on the monitor and controller card in use.

Typically, each point of energized phosphor glows for less than $1 \mathrm{msec}$. The raster scan is repeated every $13-$ 


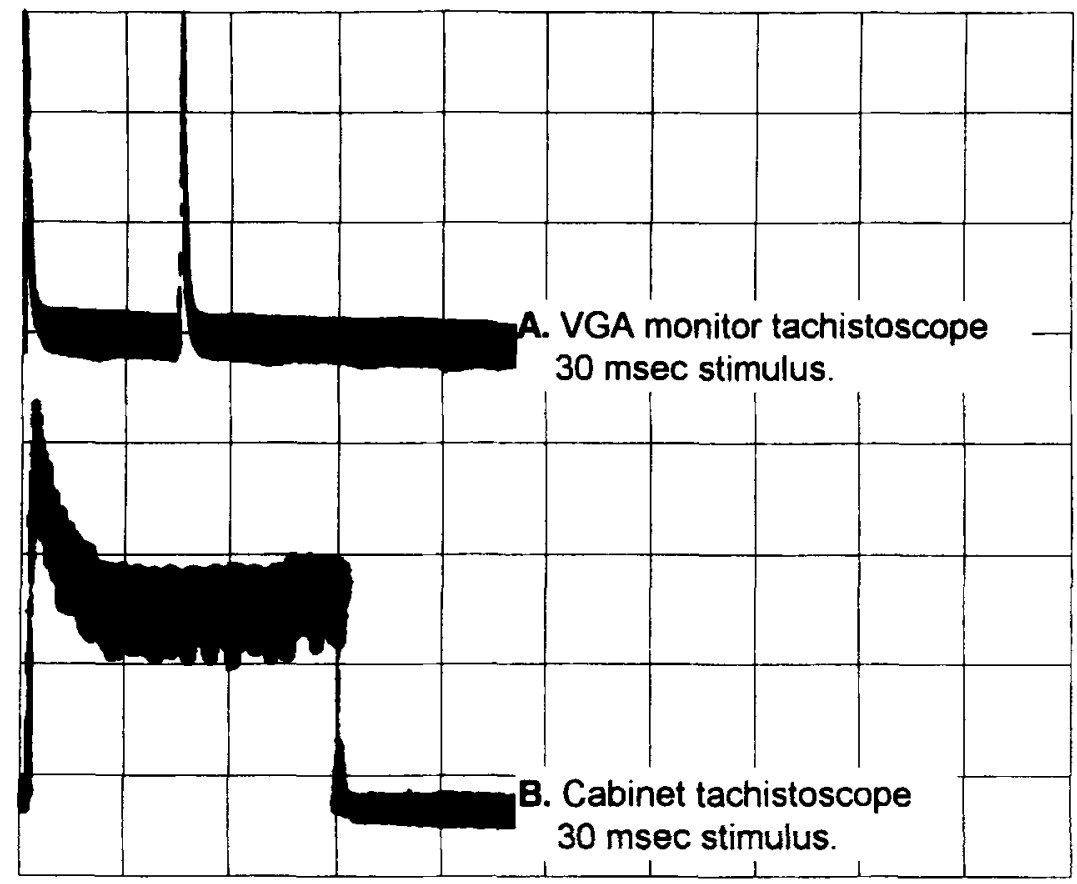

Figure 1. Brightness over time of (A) CRT and (B) cabinet tachistoscope images. Horizontal scale: $10 \mathrm{msec}$ per division. Vertical: linear brightness (unscaled).

$17 \mathrm{msec}$, completely rewriting the image each time. Therefore, a stimulus presented on a CRT essentially flashes at the rate of 60-75 times each second. The oscilloscope screen shown in Figure $1 \mathrm{~A}$ displays a plot of brightness versus time for a nominal 30 -msec stimulus presentation on a CRT screen. Note that the plot depicts two flashes spaced $15 \mathrm{msec}$ apart. By comparison, in a traditional tachistoscope of the cabinet or projection type, the stimulus image is illuminated for its duration by an essentially continuous light source. The cabinet lamps are lit, or a projector shutter is opened, for the period of stimulus exposure. Figure 1B shows the brightness of a cabinet tachistoscope stimulus over a $30-\mathrm{msec}$ interval.

\section{Nonsimultaneity of Stimulus Presentation}

In a conventional tachistoscope, the stimulus is illuminated by the flash of a light, and all parts of the stimulus are visible simultaneously. When the lights are shut off, all parts of the stimulus are removed from view simultaneously. By contrast, in a computer monitor tachistoscope, the screen image is scanned progressively, usually from top to bottom, on a line-by-line basis. In a typical computer monitor, this occurs at a rate of approximately $10 \mathrm{~mm}$ per millisecond, resulting in three separate effects of time distortion. First, there is a delay in the presentation of the stimulus that is proportional to its distance from the top of the screen (Bührer, Sparrer, \& Weitkunat, 1987; Dlhopolsky, 1989; Gabrielsson \& Jarvella, 1990). Presentation of a masking field will be delayed by a similar amount, affecting the end of presentation of the stimulis.
The second time-distortion effect occurs when more than one stimulus is presented at the same time, and the stimuli are presented on different video lines. Stimuli that are located at different distances from the top of the screen begin presentation at different time offsets from the beginning of the scan. In some studies, two or more stimuli are presented on the screen simultaneously, and the stimuli to be compared in each trial are located at different distances from the top of the raster scan (e.g., Berger \& Landolt, 1990; Brand, Bekkum, Stumpel, \& Kroeze, 1983; Eglin, 1987). For perceptual laterality studies, it is essential that the left and right visual field stimuli be presented on the same video lines to avoid issues of temporal order and differential time offset from the start of the refresh interval. For example, Berger and Landolt (1990) attempted to present one stimulus to each visual field simultaneously for $17 \mathrm{msec}$ (one screen refresh interval) on a CRT monitor, one stimulus in an upper left position and the other in a bottom right position, or vice versa; in unilateral conditions, one stimulus was presented below the other. Since the upper stimulus was written first in the single screen refresh interval, the tro stimuli were not presented simultaneously, as they would be with a traditional tachistoscope.

The third effect of time distortion is related to the height of stimuli presented top to bottom (e.g., words presented vertically, or large pictures). Researchers have used CRT monitors for lateralized vertical word presentation (Boles, 1985, 1991; Burgess \& Simpson, 1988; Lambert \& Beaumont, 1983; Parkin \& West, 1985; Wexler \& King, 1990 ). In a computer monitor with short persistence 


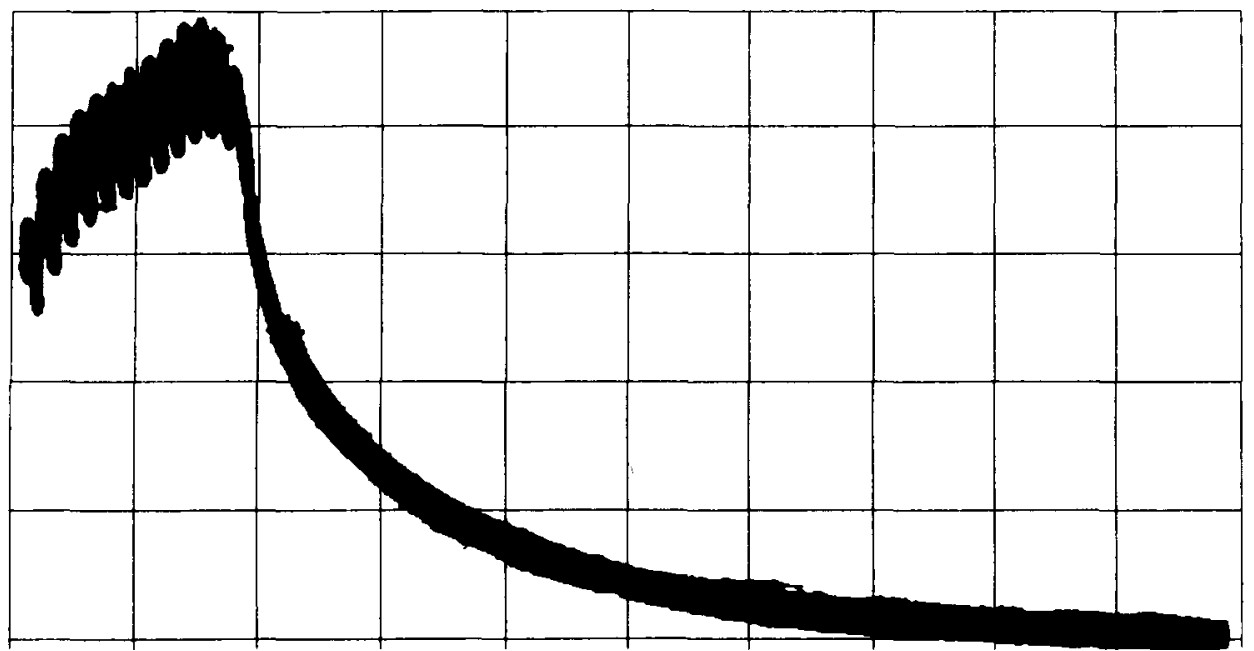

Figure 2. VGA monitor phosphor decay time for white stimulus. Horizontal scale: 0.2 msec per division. Vertical: linear brightness (unscaled).

phosphor, the top of the stimulus can stop glowing long before the bottom has been written. For instance, if a stimulus is $50 \mathrm{~mm}$ high, the bottom of the image will be written about $5 \mathrm{msec}$ after the top of the image. In a monitor with a 1-msec phosphor decay time, the top of this stimulus will have stopped glowing $4 \mathrm{msec}$ before the bottom of the image is presented.

\section{Phosphor Persistence Issues}

The electron beam in a CRT impinges on each phosphor region for a tiny amount of time--about $50 \mathrm{nsec}$ per pixel in a typical VGA monitor. The phosphor continues to glow for a much longer period, called the phosphor decay time or phosphor persistence. The brightness decays exponentially after the electron beam leaves. The decay time typically is defined as the time for brightness to decay from $90 \%$ to $10 \%$ of its maximum value.

Short persistence phosphors used in typical computer monitors (e.g., VGA color) have decay times on the order of $0.2-0.6 \mathrm{msec}$ (Figure 2). Because this is only a fraction of the time between refreshes, the result is a flashing image. The instantaneous brightness of the image changes enormously in the time between refreshes, but persistence of human vision allows it to be seen as a continuous image.

Long persistence phosphors used in some monitors have a decay time of up to $50 \mathrm{msec}$ (Lincoln \& Lane, 1980). This mostly eliminates the flashing effect caused by short persistence phosphors. However, when a stimulus is presented as a light image against a dark background, the stimulus will continue to glow for the duration of the phosphor decay time, lengthening the stimulus duration. Researchers who are conducting visual laterality studies must take the phosphor persistence effect into account, since stimulus exposure durations generally do not exceed $150 \mathrm{msec}$ (the time period required for a saccadic move- ment from central fixation to lateral gaze in the right or left visual fields [RVF or LVF]; e.g., see Sergent, 1982).

To eliminate the phosphor persistence effect, a number of researchers have presented a masking stimulus (Boles, 1985; Bruyer \& Janlin, 1989; Brysbaert \& D'Ydewalle, 1990; Burgess \& Simpson, 1988; Channon, Schugens, Daum, \& Polkey, 1990; Eglin, 1987) or a blanking flash (Babkoff \& Faust, 1988) immediately after the stimulus. When dark stimuli are used against a light background, a full white field or a pattern mask with a high ratio of white to black pixels (Segalowitz, 1987; Van Kleeck, 1989) can be flashed after the stimulus, reducing aftereffects related to long persistence phosphors. However, use of dark stimuli against a light background moves the problem of long phosphor persistence to the beginning of the exposure duration interval, since the stimulus will not appear in full contrast until the stimulus area ceases to glow. In any case, it should be noted that presenting a mask or a blanking flash after the stimulus changes the nature of the task from a simple test of stimulus identification to a backward masking paradigm.

\section{Redefining Exposure Duration}

In a conventional tachistoscope, minimum exposure durations are in the 1-msec-5-msec range. Even when timing is controlled by a computer, the exposure duration may be defined with essentially infinite resolution; for convenience, increments of $1 \mathrm{msec}$ are often used. However, since the image on a computer monitor tachistoscope flashes once every $13-17 \mathrm{msec}$, exposure durations must be defined in terms of a whole number of individual flashes and therefore must equal a multiple of the CRT refresh interval. A single refresh interval actually produces a flash of less than 1-msec duration for each picture element. The next available exposure provides two flashes 
separated by 13-17 msec, the next provides three flashes, and so on. This produces a "picket fence" effect of brightness across time (see Figure 1A).

There is no direct equivalence between the continuous exposure of a conventional tachistoscope over an interval and the group of pulsating images by which the CRT forms the same image. The CRT stimulus duration can be defined in two ways: (1) as the number of refresh intervals multiplied by the refresh interval time quantum, or (2) as the "brightness envelope" from the first flash of light to the decay of the last flash of light. Using the latter definition, the stimulus duration would be approximated using this formula:

brightness envelope duration

$=[($ total number of refresh intervals -1$)$

$\times$ refresh interval time quantum]

+ phosphor decay time

+ (height of stimulus in centimeters $\times 1 \mathrm{msec}$ )

The following example illustrates how a set of three flashes would be considered as producing different exposure durations depending on which of the two definitions is used. Suppose that there are three flashes of a stimulus $3 \mathrm{~cm}$ in height on a CRT with a $14.3-\mathrm{msec}$ refresh interval and fast decay phosphor $(<1 \mathrm{msec})$. The exposure duration is approximately $43 \mathrm{msec}$ according to the first definition and approximately $33 \mathrm{msec}$ according to the second. A stimulus $1 \mathrm{~cm}$ in height that is flashed for only one refresh interval on the monitor just described has an exposure duration of $14.3 \mathrm{msec}$ according to the first definition, but the stimulus actually glows for less than $2 \mathrm{msec}$ (second definition).

Commercially available computer tachistoscope programs use the first definition of exposure duration. For example, the Micro Experimental Laboratory User's Guide (Schneider, 1990) states that all display durations must be multiples of the screen refresh rate. Therefore, to avoid ambiguity, researchers should report exposure durations in terms of the number of refresh intervals (Corballis \& Sergent, 1989; Dlhopolsky, 1982; Segalowitz, 1987) and the actual CRT refresh interval time quantum. However, researchers should be aware that the nominal stimulus duration used by commercially available software programs overestimates the duration of the actual brightness envelope by as much as one refresh interval.

\section{Limitations of Exposure Durations That Are Multiples of the Screen Refresh Rate}

For certain studies, it is necessary to use exposure durations below the 13-17-msec refresh interval. These short exposure durations cannot be accommodated by a CRT-based tachistoscope. Studies that have determined visual thresholds on conventional tachistoscopes have varied exposure durations in intervals as short as $1-5 \mathrm{msec}$ (e.g., Natale, Gur, \& Gur, 1983; Oscar-Berman, Blumstein, \& De Luca, 1976; Oscar-Berman, Goodglass, \& Cherlow, 1973; Oscar-Berman \& Weinstein, 1985). Stimulus durations under $10 \mathrm{msec}$ have been used (e.g., Hellige \& Webster, 1979, used a 7-msec exposure duration for target letters and the masking stimulus; Regard \& Landis, 1984, and Hutner \& Oscar-Berman, 1996, used exposure durations as short as $5 \mathrm{msec}$ for words). In studies varying stimulus onset asynchronies, intervals of $0 \mathrm{msec}$ have been used, followed by increments of 5-10 msec (e.g., Hellige, 1983; Hellige \& Webster, 1979; Kostandov, Arsumanov, Genkina, Restchikova, \& Shostakovich, 1982; Oscar-Berman et al., 1976; Oscar-Berman et al., 1973). Because exposure durations on a CRT can be adjusted only in increments of 13-17 msec, these types of studies could not have been conducted with CRT-based tachistoscopes.

\section{Software Issues}

Properly designed software can limit CRT-based artifacts to those previously stated. But poorly written software can introduce other problems, such as inaccurate timing, partially formed images, or images of uneven brightness displayed at the beginning or end of a refresh interval.

If the software does not synchronize display changes with the beginning of the raster scan, and the stimulus is presented for only one screen refresh interval, then the bottom portion of the stimulus may be presented before the top portion. If stimulus presentation is not synchronized with the beginning of the raster scan, and the stimulus is presented for more than one refresh interval, then this problem may affect the appearance of the stimulus during the first or last refresh interval. For example, if the electron beam is shut off before the image is completed on the last refresh interval, the portion of the stimulus that was scanned will be brighter than the portion that was not scanned during the final interval. The lack of synchronization of display changes with the beginning of the screen refresh cycle may alter both the appearance of stimuli and actual stimulus durations from trial to trial.

If the software program does not use the actual monitor refresh rate for calculation of stimulus duration, timing inaccuracies will occur, and partial stimuli or stimuli of uneven brightness may be displayed. If the software uses a refresh rate that is shorter than the actual monitor refresh rate to calculate stimulus durations, partially formed images may be displayed when stimuli are presented for a single refresh inte ${ }_{\text {val, }}$ and images of uneven brightness may be displayed when stimuli are presented for more than one refresh interval. Similarly, if the software uses a refresh rate that is longer than the actual monitor refresh rate, stimuli of uneven brightness may be displayed.

Figure 3 shows a visual stimulus (a circle) presented by an inaccurate commercially available computer tachistoscope program. The exposure duration for the circle was 

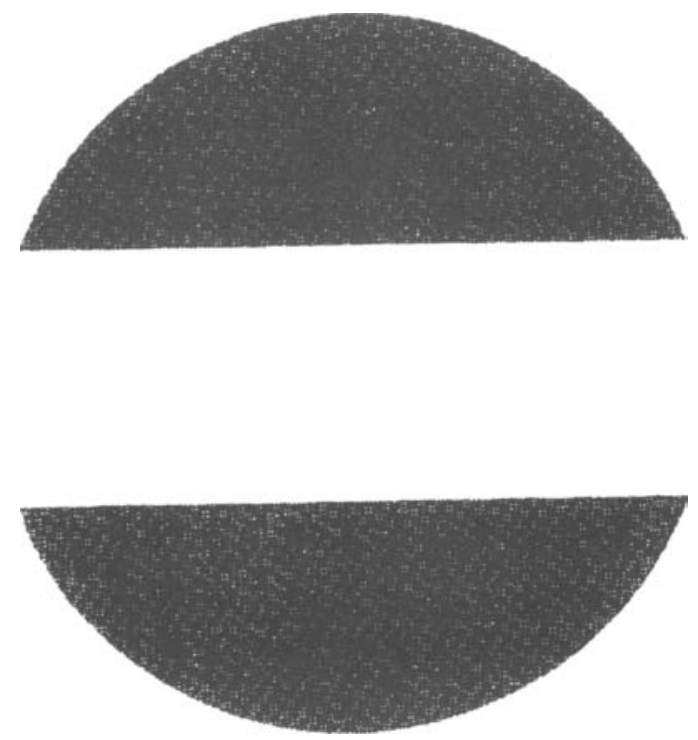

Figure 3. Visual stimulus incompletely presented because of software inaccuracy.

specified to be $15 \mathrm{msec}$ (a single refresh interval for the monitor). This image illustrates two of the problems that can be produced by inaccurate software. The bottom portion of the circle was scanned before the top portion, indicating that stimulus presentation was not synchronized with the beginning of the monitor's raster scan. Furthermore, the software did not calculate the refresh interval correctly. If the timing had been accurate, the whole circle would have been completed in one refresh interval.

In order to eliminate these problems, the time intervals allowed by software must be in whole multiples of the CRT refresh rate. Nonmultiple intervals must be rounded to the nearest whole multiple. The software must measure and use the actual monitor refresh rate for calculation of stimulus duration.

Software programs must wait for the stimulus image to be completely written to display memory before the image is presented on the CRT screen (Paredes, Miller, \& Creeger, 1990; Rensink, 1990). The refresh cycle and timing of exposure durations should begin when the raster beam is in the upper left-hand corner of the screen (Bührer et al., 1987; Dlhopolsky, 1989; Finley, 1989; Segalowitz, 1987). Furthermore, the software should specify whether reaction times are calculated from the beginning of the screen refresh cycle or from the beginning of stimulus presentation (Bührer et al., 1987; Dlhopolsky, 1989; Gabrielsson \& Jarvella, 1990). Finally, between refresh intervals, the screen must remain the same color as the stimulus background.

\section{Other Issues}

Findings of some studies using conventional tachistoscopes have not been replicated when computer monitor tachistoscopes were used for stimulus presentation. For example, Kosslyn et al. (1989) reported that when they used an Apple II computer for stimulus presentation, they failed to replicate the results of an experiment that they had conducted using a conventional tachistoscope. They subsequently conducted the same experiment four times with the Apple II computer and obtained mixed results. Sergent and Hellige (1986) noted that Chiarello (personal communication) failed to replicate the finding of a RVF (left-hemisphere) superiority for lexical discrimination tasks (Hardyck, Chiarello, Dronkers, \& Simpson, 1985) when stimuli were presented on a computer screen rather than through a projector.

In addition to the issues discussed previously, other factors may contribute to failures to replicate findings of tachistoscopic studies when stimuli are presented on CRTbased tachistoscopes rather than on conventional tachistoscopes: CRT images may be of lower resolution or contrast than those presented by conventional tachistoscopes (Sergent \& Hellige, 1986), and the pulsating images on a CRT may be processed or perceived very differently from the continuous images of a conventional tachistoscope.

\section{EXPERIMENTAL EVALUATION OF PERCEPTION OF STIMULI PRESENTED TO CENTRAL AND LATERAL VISUAL FIELDS}

The present study was conducted to determine whether the pulsating images presented on a CRT are perceived differently than the continuous images presented by a conventional tachistoscope. Although a CRT monitor and a conventional tachistoscope may have the same average brightness (equal integral of brightness over time), when stimuli are presented for nominally equivalent exposure durations, the pulses of light from a CRT are shorter but more intense than those produced by a conventional tachistoscope. Since stimuli that are presented on a computer monitor tachistoscope for nominally equivalent exposure durations are physically visible for a shorter cumulative time than those presented on a conventional tachistoscope, it was hypothesized that subjects' performance might be better when stimuli were presented on a conventional tachistoscope than when they were presented on a CRT display.

A secondary aim of this study was to determine whether the different nature of the images on the two types of tachistoscopes would affect the pattern of visual field advantage. Since the use of short exposure durations in laterality studies has been shown to favor the LVF (right hemisphere), independent of the nature of the stimuli (e.g., linguistic, visuospatial, etc.; Sergent, 1982; Sergent \& Hellige, 1986), it was hypothesized that when brief stimuli were presented on a CRT display, the pulsating nature of the stimulus would result in a laterality pattern suggesting greater right-hemisphere involvement than 
Table 1

Mean Number of Errors on the Shape Identification Task as a Function of Type of Tachistoscope, Gender, and Visual Field

\begin{tabular}{|c|c|c|c|c|c|c|}
\hline \multirow[b]{3}{*}{ Gender } & \multicolumn{6}{|c|}{ Visual Field } \\
\hline & \multicolumn{2}{|c|}{ Left } & \multicolumn{2}{|c|}{ Right } & \multicolumn{2}{|c|}{ Center } \\
\hline & $M$ & $S D$ & $M$ & $S D$ & $M$ & $S D$ \\
\hline \multicolumn{7}{|c|}{ Conventional Tachistoscope } \\
\hline Male & 10.06 & 2.32 & 10.75 & 2.57 & 7.88 & 3.12 \\
\hline Female & 10.56 & 1.63 & 9.25 & 2.35 & 7.56 & 2.25 \\
\hline \multicolumn{7}{|c|}{ Computer Monitor Tachistoscope } \\
\hline Male & 9.94 & 2.44 & 9.56 & 2.00 & 8.19 & 3.21 \\
\hline Female & 9.31 & 2.21 & 10.00 & 2.22 & 8.56 & 3.14 \\
\hline
\end{tabular}

when stimuli were presented on a traditional tachistoscope. Furthermore, stimuli requiring visuospatial processing (i.e., a difficult shape identification task) were employed to maximize the likelihood of differentiating between tachistoscopic procedures when testing the hypotheses. Since two laterality studies in our laboratory found no visual field superiority for tasks requiring identification of visuospatial stimuli when a conventional cabinet tachistoscope was used for stimulus presentation (Oscar-Berman et al., 1973; Oscar-Berman \& Weinstein, 1985), we predicted that (1) the subjects in the present experiment would again show no significant visual field advantage when the stimuli were presented with a conventional tachistoscope and (2) the subjects would show a significant LVF advantage when stimuli were presented on a computer monitor tachistoscope.

\section{Method of Phase 1}

Subjects. The subjects were 16 male and 16 female university students ranging in age from 18 to 26 years $(M=20.22, S D=2.20)$. Their years of education ranged from 13 to $19(M=14.63, S D=$ 1.68). All subjects had normal or corrected-to-normal vision, and they showed a right-hand preference on a handedness questionnaire (modified from Bryden, 1977).

Stimulus presentation. At the beginning of each trial, a fixation point (a centered black plus sign against a white background) was presented for 1,000 msec, and the experimenter said, "Focus," to remind the subject to focus on the plus sign. Next, there was a delay of $50 \mathrm{msec}$ during which the background remained white, and then a black shape was presented against a white background, either centrally or to the LVF or the RVF, for $14 \mathrm{msec}$. Immediately following presentation of the stimulus, the screen was black for $6 \mathrm{sec}$, and then a set of response choices was presented ( 15 black shapes identified by number).

The subjects were told to report the number corresponding to the shape that they had just seen, and they were told to respond as quickly as possible but to take enough time so that they would not make careless responses. The response choices remained on the screen until the experimenter pressed a button corresponding to the subject's verbal answer or for a maximum of $30 \mathrm{sec}$ if the subject had not responded.

For trials presented on the computer monitor tachistoscope, the 14-msec exposure duration entailed one refresh interval of the monitor (the brightness envelope duration is approximately $3.5 \mathrm{msec}$ ).

Stimuli and Procedure. Stimuli were 60 random shapes ( 30 sixteen-point shapes and 30 twenty-four-point shapes) created by Vanderplas and Garvin (1959). Fifteen practice trials preceded the first block of trials presented on each type of tachistoscope; practice stimuli and response choices consisted of 12 twelve-point shapes. Four blocks of trials were administered to each of the subjects. Fifteen unique shapes were presented in each block. Each block consisted of 30 trials (each of the 15 shapes was presented twice). Within each block of trials, approximately half ( 7 or 8 ) of the stimuli were sixteen-point shapes, and the remaining 7 or 8 were twentyfour-point shapes. Although each shape was presented twice in each block, if a shape was presented to the LVF initially, then it was presented to either the RVF or center position the second time. Likewise, if the stimulus was presented to the RVF or center position initially, then it was presented to one of the two remaining positions the second time. The response choices were different for the first and second presentations of each shape within a block. Within each block, 10 stimuli were presented in each position (LVF, RVF, and center). The position of presentation was randomized, with the exception that no more than three consecutive stimuli were presented in the same position.

There were six unique sets of response choices per block. Each set of response choices consisted of 15 shapes (three rows of 5 shapes, with a number from 1 to 15 below each shape). Each of the 15 response choices was $1.8 \times 1.8 \mathrm{~cm}$. The entire response matrix was $11.5 \times 8 \mathrm{~cm}$. Five of the shapes were the correct responses for trials within that block. For each correct shape, there were two similar shapes differing by one feature, two features, or several features. Thus, distinguishing among the shapes was designed to be a difficult task.

Of the four blocks of stimuli presented to each subject, two blocks were presented on a conventional cabinet tachistoscope, and the other two blocks were presented on a computer monitor tachistoscope. The order of presentation of the four blocks of trials and the order of mode of presentation (conventional vs. computer monitor tachistoscope) were counterbalanced across subjects. Half of the subjects were given trials in the following order: (1) 15 practice trials on the conventional tachistoscope, (2) 30 trials on the conventional tachistoscope, (3) 15 practice trials on the computer monitor tachistoscope, (4) 30 trials on the computer monitor tachistoscope, (5) 30 trials on the conventional tachistoscope, and (6) 30 trials on the computer monitor tachistoscope. The other half of the subjects started with trials presented on the computer monitor tachistoscope and alternated back and forth between the two types of tachistoscopes.

To ensure that any visual effects would not be confounded by differing degrees of difficulty of stimuli presented in each visual position, three sets of stimuli were used. A third of the subjects were given Set A: The four blocks of 30 trials consisted of 10 stimuli presented to the LVF, 10 stimuli presented to the RVF, and 10 stimuli presented centrally. A third of the subjects were given Set B: The 10 stimuli that had been presented to the LVF in Set A were presented centrally, the 10 stimuli that had been presented to the RVF in Set $\mathrm{A}$ were presented to the LVF, and the 10 stimuli that had been presented centrally in Set A were presented to the RVF. A third of the subjects were given Set $C$ : The 10 stimuli that had been presented to the LVF in Set A were presented to the RVF, the 10 stimuli that had been presented to the RVF in Set A were presented centrally, and the 10 stimuli that had been presented centrally in Set A were presented to the LVF. An equal number of males and females were tested with Sets A, B, and C.

Each stimulus was $2.5 \times 2.5 \mathrm{~cm}$ (approximately $68 \times 68$ pixels). For stimuli presented to the LVF or the RVF, the visual angle from the fixation marker to the center of the stimulus was $3.1^{\circ}$. The visual angle subtended by the stimuli was the same in both types of tachistoscopes.

Apparatus. A four-field Gerbrands cabinet tachistoscope and a computer monitor tachistoscope were used to present visual stimuli. The Micro Experimental Laboratory (MEL) software program 
Table 2

Mean Number of Errors on the Shape Identification

Task as a Function of Type of Tachistoscope,

Exposure Duration, and Visual Field

\begin{tabular}{|c|c|c|c|c|c|c|}
\hline \multirow{3}{*}{$\begin{array}{c}\text { Exposure Duration } \\
(\mathrm{msec})\end{array}$} & & & Vis & & & \\
\hline & \multicolumn{2}{|c|}{ Left } & \multicolumn{2}{|c|}{ Right } & \multicolumn{2}{|c|}{ Center } \\
\hline & $M$ & $S D$ & $M$ & $S D$ & $M$ & $S D$ \\
\hline \multicolumn{7}{|c|}{ Conventional Tachistoscope } \\
\hline 14 & 10.75 & 1.75 & 9.88 & 1.96 & 8.00 & 2.14 \\
\hline 29 & 8.38 & 2.93 & 9.00 & 2.00 & 7.25 & 3.85 \\
\hline 43 & 8.13 & 1.81 & 7.63 & 2.33 & 6.00 & 2.39 \\
\hline \multicolumn{7}{|c|}{ Computer Monitor Tachistoscope } \\
\hline 14 & 9.63 & 2.00 & 9.50 & 1.51 & 9.13 & 2.10 \\
\hline 29 & 8.50 & 2.73 & 9.88 & 3.80 & 5.63 & 2.83 \\
\hline 43 & 7.13 & 1.13 & 7.63 & 2.26 & 6.75 & 1.39 \\
\hline
\end{tabular}

was used to present stimuli on the computer monitor tachistoscope. Stimuli were presented on a Sony Trinitron Multiscan monitor with a $70-\mathrm{Hz}(14.3-\mathrm{msec}$ interval) refresh rate in VGA mode $(640 \times$ 480 pixels) and fast decay phosphor (less than $1 \mathrm{msec}$ ).

Figures 1 and 2 are photographs of an oscilloscope screen. The vertical signal was generated by a phototransitor biased with 10 $\mathrm{mA}$ direct current, fed to the vertical input. Further details are available on request.

For both types of tachistoscopes, the distance from the stimulus to the subject's eyes was $81 \mathrm{~cm}$ (32 in.). The subjects viewed the stimulus through an eyepiece. For computer monitor tachistoscope presentations, a viewing hood with an attached eyepiece was positioned against the monitor to emulate the style of presentation of the conventional tachistoscope. During the experiment, the overhead light was shut off.

Two presentation parameters (exposure duration and brightness) were designed to be as equivalent as possible for the two types of tachistoscopes. The exposure duration of the cabinet tachistoscope was made equal to the nominal CRT stimulus duration used by a commercially available software program (MEL) (i.e., exposure duration equals the number of refresh intervals multiplied by the refresh interval time quantum). The brightness of the cabinet tachistoscope was made equal to the time integral brightness of the pulsating CRT image, as measured by a light meter with a low-pass filtering function (brightness measurements were taken in EV units, then converted to $\mathrm{cd} / \mathrm{m}^{2}$ ). Stimulus luminance was adjusted to $7.2 \mathrm{~cd} / \mathrm{m}^{2}$ (measured as $5 \frac{2}{3} \mathrm{EV}$ ) for both types of tachistoscopes. Black levels were matched as closely as possible to $0.44 \mathrm{~cd} / \mathrm{m}^{2}(12 / 3$ EV) for the cabinet tachistoscope and $0.35 \mathrm{~cd} / \mathrm{m}^{2}(1 / 3 \mathrm{EV})$ for the CRT display. The resulting contrast ratio was $16: 1$ for the cabinet tachistoscope and 20:1 for the CRT display.

\section{Results and Discussion of Phase 1}

Table 1 presents the mean number of errors on the shape identification task as a function of type of tachistoscope (computer monitor vs. conventional), gender, and visual field (LVF, RVF, center). A repeated measures analysis of variance (ANOVA) was computed with gender as the between-subjects factor and visual field and type of tachistoscope as the within-subjects factors. The results indicated that there was a significant main effect of visual field $[F(2,60)=20.59, p<.001]$. Newman-Keuls post hoc comparisons among means indicated that the subjects' performance was better when stimuli were presented cen- trally than when they were presented to either visual field $(p<.01)$; however, performance did not differ significantly in the LVF and RVF conditions. None of the other main or interaction effects was significant.

When stimuli were presented for $14 \mathrm{msec}$, the error rate and laterality pattern did not differ as a function of mode of presentation of stimuli. This finding was surprising, considering that stimuli were physically visible for a shorter period of time when they were presented on the computer monitor tachistoscope.

A second phase of the experiment was conducted to determine whether differences in performance based on mode of presentation would become apparent when the exposure duration required more than one refresh of the computer screen. This second phase examined whether the pulsating images produced by two or three refreshes of the CRT would result in poorer performance than the continuous images presented for nominally equivalent exposure durations on a traditional cabinet tachistoscope.

\section{Method of Phase 2}

Subjects. The subjects consisted of 8 randomly selected students who had participated in Experiment 1 ( 4 males and 4 females), and an additional 16 university students ( 8 males and 8 females). All subjects were right-handed and had normal or corrected-to-normal vision. Their ages ranged from 18 to 23 years $(M=20.58, S D=$ $1.72)$, and their years of education ranged from 13 to $17(M=14.88$, $S D=1.42$ ).

Stimuli and Procedure. The procedure was identical to that described for Experiment 1, except that there were three conditions differing in the exposure duration of stimuli. Eight subjects (4 males and 4 females) were tested in each of the exposure duration conditions: 14,29 , and $43 \mathrm{msec}$. For stimuli presented on the CRT, the 14-msec condition entailed one refresh interval of the monitor (brightness envelope duration is approximately $3.5 \mathrm{msec}$ ); the 29 msec condition entailed two refresh intervals (brightness envelope duration is approximately $18 \mathrm{msec}$ ); and the $43-\mathrm{msec}$ condition entailed three refresh intervals (brightness envelope duration is approximately $32 \mathrm{msec}$ ).

Eight subjects who had participated in Experiment 1 were randomly selected to represent performance in the 14-msec condition, and an additional 16 subjects were randomly assigned to either the 29- or the 43-msec condition. Results of one-way ANOVAs indi- 
cated that the subjects in the three exposure duration conditions did not differ significantly in age or years of education.

\section{Results and Discussion of Phase 2}

Table 2 presents the mean number of errors on the shape identification task as a function of type of tachistoscope, exposure duration (14, 29, or $43 \mathrm{msec})$, and visual field. An ANOVA was computed with exposure duration as the between-subjects factor and visual field and type of tachistoscope as the within-subjects factors. Gender was not included as a factor in the ANOVA due to the fact that the cell sizes would be too small for a meaningful analysis of this factor. The results indicated that there were significant main effects of exposure duration $[F(2,21)=$ $4.19, p<.05]$ and visual field $[F(2,42)=14.09, p<$ $.001]$. Newman-Keuls post hoc comparisons among means indicated that the subjects in the 43-msec exposure duration condition performed significantly better than the subjects in the $14-\mathrm{msec}$ condition $(p<.01)$. The error rate was significantly lower when stimuli were presented centrally than when they were presented to the left or right visual field $(p<.01)$. Performance did not differ in the LVF and RVF conditions.

\section{GENERAL DISCUSSION}

For the three exposure durations tested, the subjects' error rates and their laterality patterns did not differ as a function of whether stimuli were presented on the conventional tachistoscope or on the computer monitor tachistoscope. To achieve the same average brightness, CRT displays use brief periods of high intensity separated by dark periods, whereas cabinet tachistoscope displays use a lower luminance that remains constant across the exposure duration. The results of this study suggest that even though stimuli presented on a computer monitor tachistoscope may be physically visible for a shorter period of time than those presented on a conventional tachistoscope, they may not be perceived differently. The visual system does not appear to respond differently to the different kinds of intensity profiles that characterize the two types of tachistoscopes.

Contrary to our prediction, the subjects did not perceive stimuli better when they were presented on the conventional tachistoscope than when they were presented on the CRT; this was the case regardless of whether the exposure duration entailed one, two, or three refreshes of the CRT. The results suggest that subjects do not detect the rapid variations in intensity that characterize visual presentation on a CRT (i.e., the pulsating nature of the image). When the exposure duration involves more than one refresh of the CRT, the visual system appears to integrate over the pulsation. This may be due to factors such as persistence of vision. The term visual persistence refers to the fact that a brief visual display may remain visible for at least 60-100 msec longer after termination of the phys- ical stimulus (Ganz, 1975). Due to visual persistence, brief stimuli that are sequentially presented and do not overlap may be perceived as occurring simultaneously due to the temporal integration of the stimuli into a single perceptual experience (e.g., Cornsweet, 1970; Dixon \& Di Lollo, 1994).

The results also do not support our second hypothesis. We predicted that the pulsating nature of stimuli presented on a CRT would result in a laterality pattern suggesting greater right hemisphere involvement than when stimuli were presented on a traditional tachistoscope (i.e., we predicted that while there would be no visual field advantage when the stimuli were presented on a conventional tachistoscope, there would be a LVF advantage when the stimuli were presented on a CRT). Our finding that there was no visual field advantage for the shape identification task using either tachistoscopic presentation device provides additional evidence that experiments using either type of tachistoscope measure equivalent perceptual processes. Other studies in our laboratory have also found an absence of visual field advantage when using visuospatial stimuli, such as Vanderplas and Garvin's (1959) random shapes presented on a conventional tachistoscope for brief exposure durations (Oscar-Berman et al., 1973). It is likely that both hemispheres contribute to the processing of these shapes, because they can be identified using both visuospatial and verbal information. While the right hemisphere is dominant for visuospatial processing and the left hemisphere is dominant for verbal processing, evidence indicates that the left hemisphere also contributes to spatial processing on standard visuospatial tasks (Mehta \& Newcombe, 1991). Furthermore, during a debriefing period of the present study, many subjects reported that they tried to remember the random shapes by associating each shape with something to which they could assign a verbal label. Since the response choices appeared on the screen $6 \mathrm{sec}$ after a stimulus shape was presented, there was opportunity for left hemispheric involvement in the task

Further studies are needed to determine whether the different characteristics of conventional and computer monitor tachistoscopes affect the way that other types of stimulus materials (e.g., verbal stimuli) are perceived. If further research supports our conclusion that perception of visual stimuli presented as continuous images on a conventional tachistoscope is equivalent to perception of visual stimuli presented as pulsating images on a CRT, then researchers may prefer to use computer monitor tachistoscopes for a variety of reasons, including the following: (1) Stimuli are easy to make for computer monitor tachistoscopes (e.g., colors, fonts, shapes), and scanners can be used to create and store complex visual images (e.g., faces). (2) The intertrial intervals are more consistent with computer monitor tachistoscopes than with cabinet tachistoscopes (where the experimenter controls insertion of the stimuli into the appropriate channels). 
(3) Longer sequences of stimuli can be presented on computer monitor tachistoscopes than on cabinet tachistoscopes (which generally have two to four channels, limiting the amount of information that can be displayed per trial). (4) The location of stimuli on the screen is more accurate when computer monitor tachistoscopes are used.

Future studies may determine which of the definitions of exposure duration described in this paper is most comparable to exposure durations of conventional tachistoscopes. Meanwhile, to improve comparability and replicability of experiments, it is recommended that the following 13 factors be reported in articles describing CRT-based tachistoscope experiments: (1) monitor screen refresh rate (available from the computer as a display property); (2) display mode and resolution (available from the computer as a display property); (3) exposure duration defined in terms of the number of screen refreshes multiplied by the refresh interval time quantum; (4) phosphor decay rate for the colors used (available from computer monitor manufacturers); (5) stimulus size in terms of number of pixels and visual angle; (6) location of stimulus on the screen; (7) time delay from the top of the screen to the beginning of the stimulus [refresh interval $\times$ (distance of stimulus from top of screen/height of screen)]; (8) whether reaction time calculation starts after the vertical retrace signal or at the start of stimulus presentation (available from experiment software manufacturer); (9) luminance of stimulus materials (use commercially available luminance meter); (10) colors of stimuli and of background; (11) colors of pre- and postexposure fields; (12) distance of subjects' eyes from the screen; and (13) use of a chinrest or viewing hood.

\section{REFERENCES}

BaBKoFf, H., \& FAUST, M. (1988). Lexical decision and visual hemifield: An examination of the RT-accuracy relationship. Neuropsychologia, 26, 711-725.

BERGER, J. M., \& LANDOLT, M. (1990). Bilateral processing of numbers: Parallel processing versus functional unity. Cortex, 26, 555-566.

BOLES, D. B. (1985). The effects of display and report order asymmetries on lateralized word recognition. Brain \& Language, 26, 106-116.

BoLEs, D. B. (1991). Factor analysis and the cerebral hemispheres: Pilot study and parietal functions. Neuropsychologia, 29, 59-91.

Brand, N., Bekkum, I. V., Stumpel, M., \& Kroeze, J. H. A. (1983). Word matching and lexical decisions: A visual half-field study. Brain \& Language, 18, 199-211.

BRUYER, R,, \& JANLIN, D. (1989). Lateral differences in lexical access: Word length vs. stimulus length. Brain \& Language, 37, 258-265.

BRYDEN, M. P. (1977). Measuring handedness with questionnaires. Neuropsychologia, 15, 617-624.

BrysbaerT, M., \& D'Ydewalle, G. (1990). Tachistoscopic presentation of verbal stimuli for assessing cerebral dominance: Reliability data and some practical recommendations. Neuropsychologia, $\mathbf{2 8}$, 443-455.

Bührer, M., SPARrer, B., \& WeitKunat, R. (1987). Interval timing routines for the IBM PC/XT/AT microcomputer family. Behavior Research Methods, Instruments, \& Computers, 19, 327-334.

Burgess, C., \& Simpson, G. B. (1988). Cerebral hemispheric mechanisms in the retrieval of ambiguous word meanings. Brain \& Language, 33, 86-103.
Channon, S., Schugens, M. M., Daum, I., \& Polkey, C. E. (1990). Lateralization of language functioning by the Wada procedure and divided visual field presentation of a verbal task. Cortex, 26, 147151.

Corballis, M. C., \& Sergent, J. (1989). Hemispheric specialization for mental rotation. Cortex, 25, 15-25.

Cornsweet, T. N. (1970). Visual perception. New York: Academic Press.

Dixon, P., \& Di Lollo, V. (1994). Beyond visible persistence: An alternative account of temporal integration and segregation in visual processing. Cognitive Psychology, 26, 33-63.

Dlhopolsky, J. G. (1982). Software synchronizing of video displays and Z-80 processing in the Model III TRS-80. Behavior Research Methods \& Instrumentation, 14, 539-544.

DLHOPOLSKY, J. G. (1989). Synchronizing stimulus displays with millisecond timer software for the IBM PC. Behavior Research Methods, Instruments, \& Computers, 21, 441-446.

EGLIN, M. (1987). Interference and priming within and across visual fields in a lexical decision task. Neuropsychologia, 25, 613-624.

FINLEY, G. P. (1989). Tachistoscopic software for the Hercules display controller. Behavior Research Methods, Instruments, \& Computers, 21, 387-390.

Gabrielsson, J., \& Jarvella, R. J. (1990). How to obtain nearmillisecond precision on the IBM PC with visual stimuli not exceeding one printed line. Behavior Research Methods, Instruments, \& Computers, 22, 520-525.

GaNZ, L. (1975). Temporal factors in visual perception. In E. C. Carterette \& M. P. Friedman (Eds.), Handbook of perception: Vol V. Seeing (pp. 169-231). New York: Academic Press.

Hardyck, C., Chiarello, C., Dronkers, N., \& Simpson, G. (1985). Orienting attention within visual fields: The limits of interhemispheric transfer. Journal of Experimental Psychology: Human Perception \& Performance, 11, 650-666.

Hellige, J. B. (1983). Feature similarity and laterality effects in visual masking. Neuropsychologia, 21, 633-639.

Hellige, J. B., \& WeBSTER, R. (1979). Right hemisphere superiority for initial stages of letter processing. Neuropsychologia, 17, 653-660.

HUtNer, N., \& OSCAR-BERMAN, M. (1996). Visual laterality patterns for the perception of emotional words in alcoholic and aging individuals. Journal of Studies on Alcohol, 57, 144-154.

Kosslyn, S. M., Koenig, O., Barrett, A., Cave, C. B., Tang, J., GABRIELI, J. D. E. (1989). Evidence of two types of spatial representations: Hemispheric specialization for categorical and coordinate relations. Journal of Experimental Psychology: Human Perception \& Performance, 15, 723-735.

Kostandov, E. A., Arsumanov, Y. L., Genkina, O. A., Restchikova, T. N., \& Shostakovich, G. S. (1982). The effects of alcohol on hemispheric functional asymmetry. Journal of Studies on Alcohol, 43, 411-426.

LAmbert, A. J., \& Beaumont, J. G. (1983). Imageability does not interact with visual field in lateral word recognition with oral report. Brain \& Language, 20, 115-142.

Lincoln, C. E., \& LANe, D. M. (1980). Reaction time measurement errors resulting from the use of CRT displays. Behavior Research Methods \& Instrumentation, 12, 55-57.

Menta, Z., \& Newcombe, F. (1991). A role for the left hemisphere in spatial processing. Cortex, 27, 153-167.

Natale, M., Gur, R. E., \& Gur, R. C. (1983). Hemispheric asymmetries in processing emotional expressions. Neuropsychologia, 21, 555-565.

Oscar-Berman, M., Blumstein, S., \& De Luca, D. (1976). Iconic recognition of musical symbols in the lateral visual fields. Cortex, 12, 241-248.

Oscar-Berman, M., Goonglass, H., \& Cherlow, D. G. (1973). Perceptual laterality and iconic recognition of visual materials by Korsakoff patients and normal adults. Journal of Comparative \& Physiological Psychology, 82, 316-321.

Oscar-Berman, M., \& Weinstein, A. (1985). Visual processing, mem- 
ory, and lateralization in alcoholism and aging. Developmental Neuropsychology, 1, 99-112.

Paredes, D. R., Miller, K. F., \& Creeger, C. (1990). Graphic precision: Controlling stimulus displays on IBM PC-compatible computers. Behavior Research Methods, Instruments, \& Computers, 22, 319-322.

PARKIN, A. J., \& WEST, S. (1985). Effects of spelling-to-sound regularity on word identification following brief presentation in the right or left visual field. Neuropsychologia, 23, 279-283.

REGARD, M., \& LANDIS, T. (1984). Experimentally induced semantic paralexias in normals: A property of the right hemisphere. Cortex, 20, 263-270.

RENSINK, R. A. (1990). Toolbox-based routines for Macintosh timing and display. Behavior Research Methods, Instruments, \& Computers, 22, $105-117$.

SCHNEIDER, W. (1990). MEL user's guide: Computer techniques for real time psychological experimentation. Pittsburgh: Psychology Software Tools.

Segalowitz, S. J. (1987). IBM PC tachistoscope: Text stimuli. Behavior Research Methods, Instruments, \& Computers, 19, 383-388.
SERGENT, J. (1982). Theoretical and methodological consequences of variations in exposure duration in visual laterality studies. Perception \& Psychophysics, 31, 451-461.

Sergent, J., \& Hellige, J. B. (1986). Role of input factors in visualfield asymmetries. Brain \& Cognition, 5, 174-199.

VANDERPLAS, J. M., \& GaRVIN, E. A. (1959). The association value of random shapes. Journal of Experimental Psychology, 57, 147-154.

VAN KLEECK, M. H. (1989). Hemispheric differences in global versus local processing of hierarchical visual stimuli by normal subjects: New data and a meta-analysis of previous studies. Neuropsychologia, 27, 1165-1178.

WEXLER, B. E., \& KING, G. P. (1990). Within-modal and cross-modal consistency in the direction and magnitude of perceptual asymmetry. Neuropsychologia, 28, 71-80.

(Manuscript received October 6, 1997; revision accepted for publication June 22, 1998.) 